\title{
Efficacy of graphene oxide-loaded cationic antimicrobial peptide AWRK6 on the neutralization of endotoxin activity and in the treatment of sepsis
}

\author{
Bo Song ${ }^{1}$, Hongli Zhao ${ }^{2}$, Haiyan Yang ${ }^{1}$, Shengji Wang ${ }^{3}$ \\ ${ }^{1}$ Department of Emergency, Yantaishan Hospital, Yantai, Shandong Province, China \\ ${ }^{2}$ Department of Senile Diseases, Dongying City Shengli Hospital, Dongying, Shandong Province, China \\ ${ }^{3}$ Department of Emergency, Linyi People's Hospital, Linyi, Shandong Province, China
}

Correspondence to: Shengji Wang; email: shengoyta828276@163.com, https://orcid.org/0000-0002-5866-0760

Keywords: graphene, AWRK6, AWRK6/GO, septicemia, endotoxin

Received: April 8, $2021 \quad$ Accepted: July 2, $2021 \quad$ Published: August 13, 2021

Copyright: (C) 2021 Song et al. This is an open access article distributed under the terms of the Creative Commons Attribution License (CC BY 3.0), which permits unrestricted use, distribution, and reproduction in any medium, provided the original author and source are credited.

\section{ABSTRACT}

Objective: This study is to assess the therapeutic effect of graphene oxide (GO) loaded with AWRK6 on endotoxininduced sepsis.

Method: AWRK6/GO was prepared by GO loaded AWRK6, with the structure characterization of AWRK6/GO conducted by atomic force microscope (AFM) and ultraviolet spectrophotometer, the sustained release rate of AWRK6/GO detected by high performance liquid chromatography (HPLC), and the neutralization ability of AWRK6/GO to lipopolysaccharide (LPS) tested by in vitro experiments. The levels of IL-8 and TNF- $\alpha$ in mouse cells after drug intervention were detected by ELISA; a LPS mouse model was established to observe the effects of drug intervention on the survival cycle and survival rate of mice.

Results: The sustained drug release rate of AWRK6/GO reached $85 \%$ within 24 hours observed under in vitro conditions, with an efficient neutralization effect to LPS $(P<0.01)$; Compared with the control group, the intervention of LPS succeeded in remarkably elevating the levels of IL-8 and TNF- $\alpha$ in the whole blood and macrophages of the mice $(P<0.01)$, whose survival cycle and survival rate consequently observed an obvious decline $(P<0.01)$; The intervention with AWRK6 or AWRK6/GO predominantly brought down the levels of IL-8 and TNF- $\alpha$ in the whole blood and macrophages of mice given LPS $(P<0.01)$, resulting in an elevation of the survival rate and survival time $(P<0.01)$.

Conclusion: GO loaded with cationic antimicrobial peptide AWRK6 exerts a rosy neutralization effect on endotoxin activity, with no obvious side effects on mice observed, which is of certain application value in the treatment of sepsis.

\section{INTRODUCTION}

To date, the treatment of sepsis, a disease of host immune disorders caused by bacterial infection, an array of therapeutic targets applied in clinical practice notwithstanding, still fails to yield an ideal outcome $[1,2]$. Endotoxin, also known as LPS, is an important component of the cell wall of Gram-negative bacteria and an essential inflammatory factor in the body [3].
Studies have confirmed that a small amount of endotoxin can induce a series of inflammatory reactions in the human body, leading to septic shock or even death of patients in severe cases [4]. Hence, sepsis triggered by endotoxin has become a world-wide medical challenge which consequently requires an excavation of a therapeutic agent that can ensure a substantial interception of the stimulation from LPS to the body's immune system. 
Antibacterial peptides, a key part of the body's immune defense with disadvantages to the drug-resistance of pathogenic bacteria, can eliminate the pathogens by the disruption of the cell membrane in direct interaction and the regulation with the host immune system $[5,6]$. Recent studies have shown that antimicrobial peptides intervention, long appreciated by its excellent antiinflammatory effects on the substantial inhibition of endotoxin activity in bacteria extermination and its efficacy of diminishing the production of proinflammatory cytokines by inhibiting the activation of monocytes and macrophages [7, 8], has therefore become a promising antimicrobial strategy in clinical practice. AWRK6 (SWVGKHGKKFGLKKHKKH) is a new type of cationic antibacterial peptide, which is transformed from the antibacterial peptide dybowskin2CDYa (SAVGRHGRRFGLRKHRKH) with strong antibacterial activity [9]. Graphene, the thinnest nanomaterial with only one atom thickness, is the basic unit of many nanomaterials [10]. It has been proven by in-depth research to have a wide range of applications in many fields such as medicine and chemical engineering [11]. GO exerts a tremendous fascination on the academia with its excellent biocompatibility, a stable dispersity in an aqueous solution, and a large specific surface area that can be used to load small molecule drugs $[12,13]$. To elevate the inhibition effect of AWRK6 on LPS, this study focuses on graphene nanoparticles loaded with AWRK6, and evaluates its effect in neutralizing endotoxin activity and treating sepsis, with an aim to provide a reference for the treatment of sepsis in the clinic.

\section{RESULTS}

\section{Structural characterization of AWRK6/GO}

The AWRK6/GO AFM characterization, UV characterization, and drug release rate changes were shown in Figure 1A-1D. Closer inspection of Figure 1 presented a remarkable sustained release rate of AWRK6/GO 85\% within 22 hours. Meanwhile, we identified the half-life of AWRK6/GO was 720 minutes.

\section{The inhibitory effect of AWRK6/GO on LPS activity in vitro}

The results from Figure 2 showed that compared with the LPS control group, the LPS concentration in the GO group observed no obvious changes $(P>0.05)$, while the LPS concentration in the AWRK6 or AWRK6/GO group obtained an apparent decrease $(P<0.01)$, in which a greater fall of the LPS level in the AWRK6/GO group was found $(P<0.01)$.
A

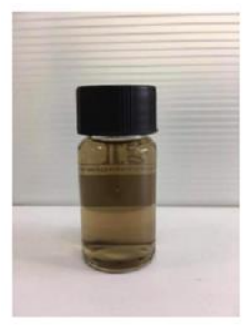

B

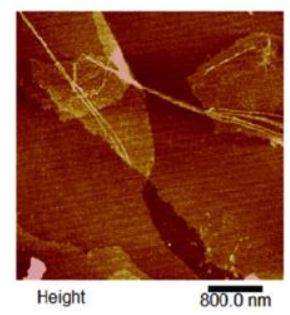

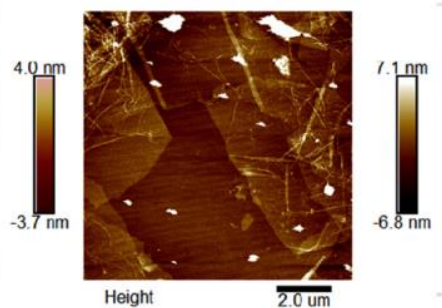

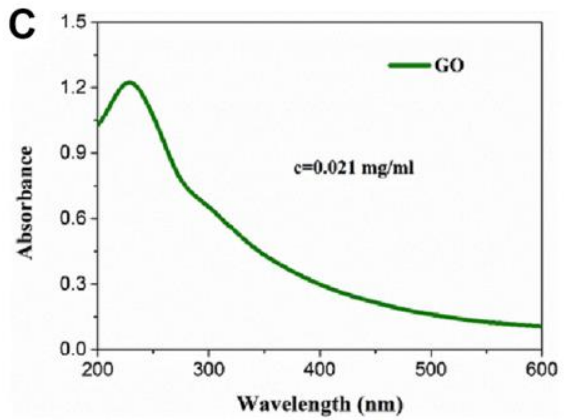

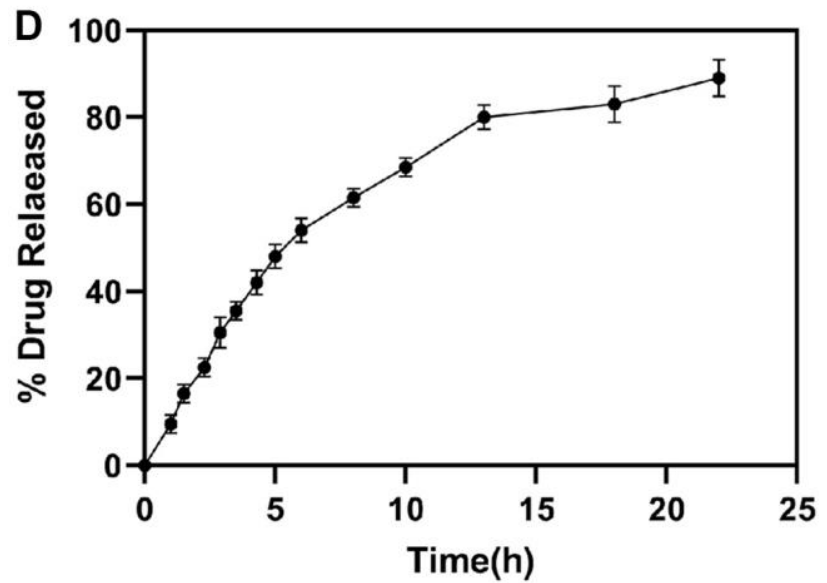

Figure 1. AWRK6/GO characterization and drug release rate (A-D). Note: (A) AWRK6/GO sample; (B) AWRK6/GO. 
The effect of AWRK6/GO intervention on the levels of inflammatory factors in the whole blood and macrophages of LPS mice

The results in Figure 3A, 3B showed that compared with the control group, the serum levels of inflammatory factors IL-8 and TNF- $\alpha$ in the mice treated with LPS were notably increased $(P<0.01)$; By contrast to the LPS control group, no evidence of apparent changes in the serum levels of IL-8 and TNF- $\alpha$ in the GO group was detected $(P>0.05)$. AWRK6 or AWRK6/GO yielded a markedly decline of the serum levels of IL- 8 and TNF- $\alpha$ in mice $(P<0.01)$, in which AWRK6/GO garnered a more prominent result $(P<0.01)$.
The effect of AWRK6/GO intervention on the prognosis and survival of LPS mice

All mice were injected with a lethal dose of $0.5 \mathrm{~mL}$ of LPS $(50 \mathrm{mg} / \mathrm{kg}$ ). In the LPS control group, all mice died within 40 hours compared with the 56 hours of the GO intervention group. However, the group with AWRK6 or AWRK6/GO intervention successfully extended the survival time to over 168 hours. In comparison with mice in the LPS control group, no significant changes were detected in terms of the survival period and survival rate of the mice treated with GO $(P>0.05)$, while the AWRK6 or AWRK6/GO yielded a desirable outcome regarding the long-term survival rate and

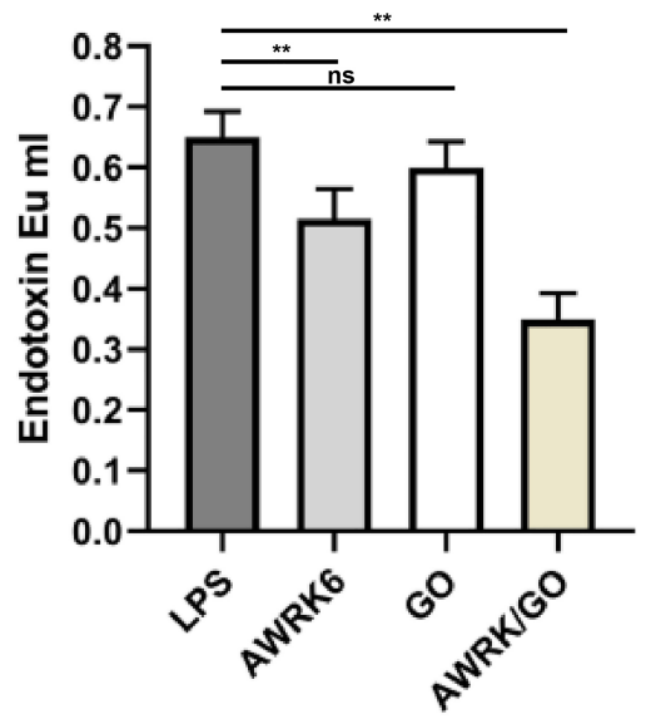

Figure 2. Inhibitory effect of AWRK6/GO on LPS activity in in vitro experiments.

A E

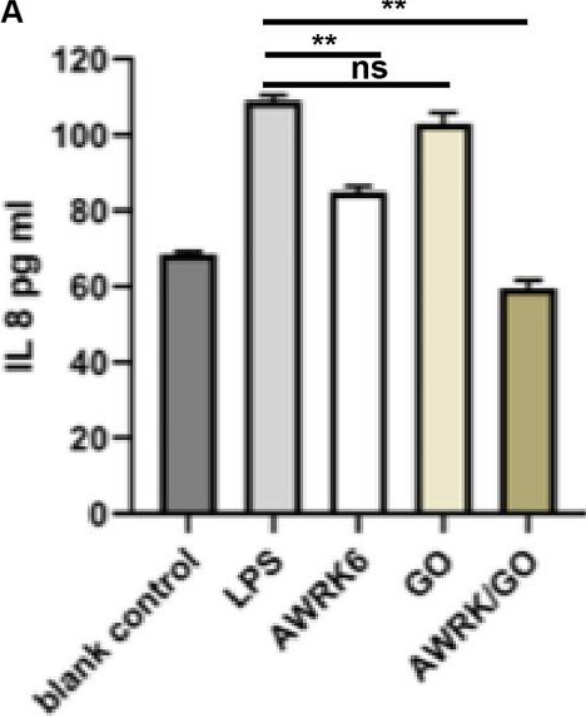

B

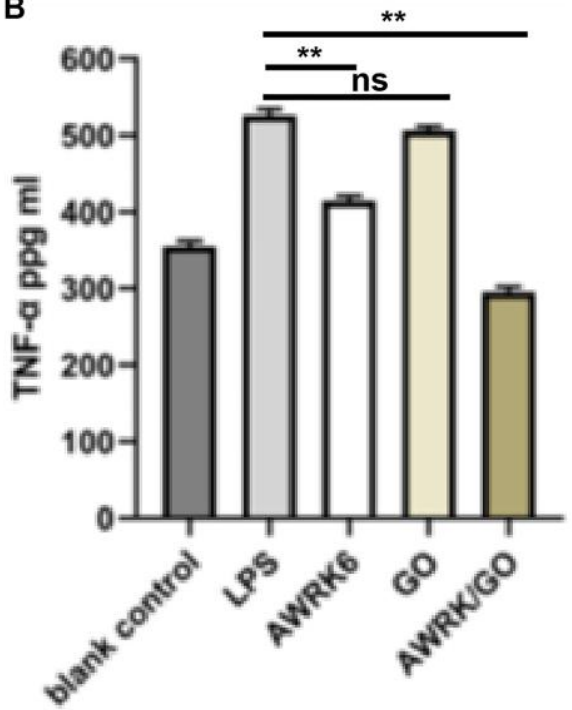

Figure 3. The effect of AWRK6/GO intervention on the levels of inflammatory factors in the whole blood and macrophages of LPS mice. Note: (A) IL-8 expression level; (B) TNF- $\alpha$ level. 
survival rate of the mice $(P<0.01)$, in which AWRK6/GO witnessed a greater increase than AWRK6 $(P<0.01)$. See Figure 4.

The effect of AWRK6/GO on the activity of liver cells, spleen cells and macrophages in LPS mice

The results in Figure 5A-5C showed that compared with the control group, 10, 20 and $30 \mu \mathrm{g} / \mathrm{mL}$ AWRK6/GO exerted no significant inhibitory effect on the activity of mouse liver cells and lymphocytes $(P>0.05)$, while the activity of macrophages was suppressed when the AWRK6/GO concentration reached to $40 \mu \mathrm{g} / \mathrm{mL}$ $(P<0.05)$.

The effect of AWRK6/GO on mouse organs and tissues

The effects of AWRK6/GO on mouse heart, liver, spleen, lung and kidney tissues were shown in Figure 6A-6E, which was indicative of a rather hidden toxic effects of AWRK6/GO on the organs of mice $(P>0.05)$.

\section{Survival Function}

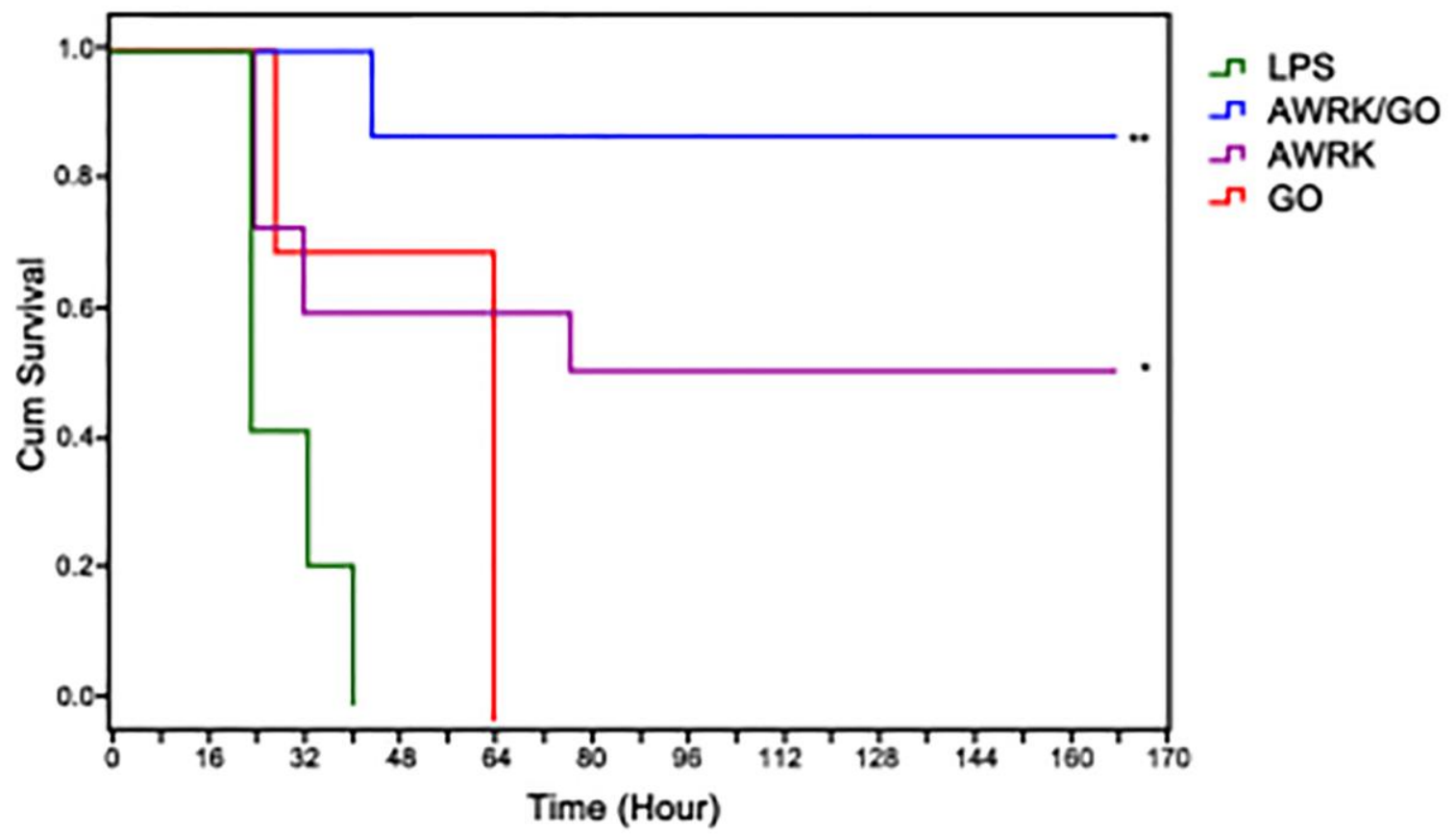

Figure 4. The effect of AWRK6/GO intervention on the prognosis and survival of LPS mice.

A

liver cell

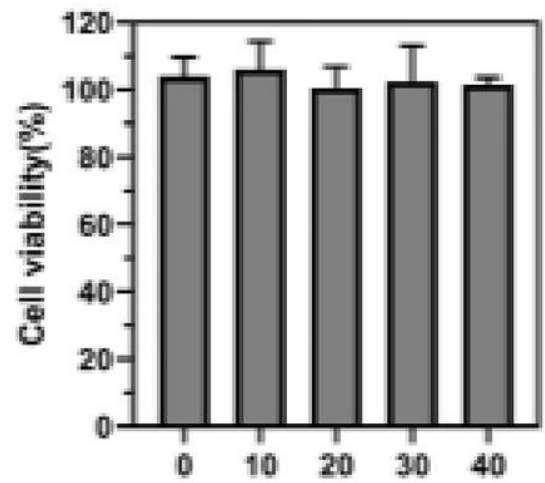

AWRKG/Go concentration( $\mu \mathrm{mm})$
B

Splenic lymphocyte

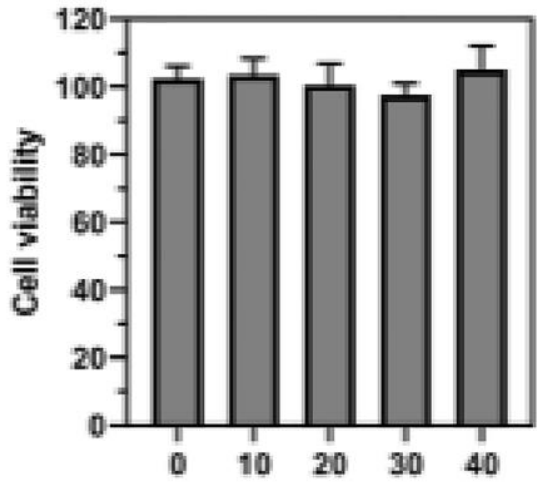

AWRKGico concentration(um)

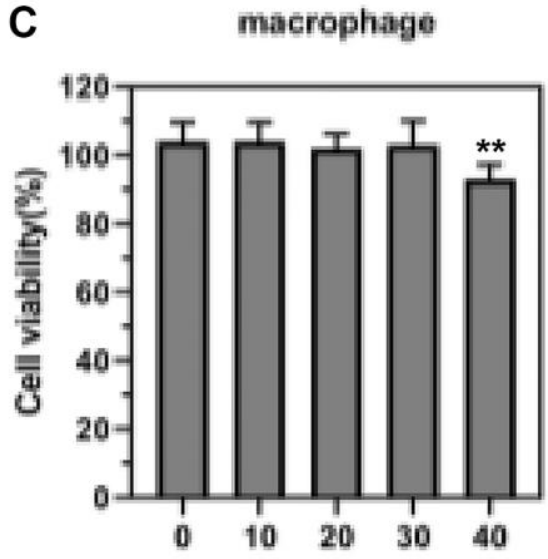

AWRikioo concentration(jum)

Figure 5. The effect of AWRK6/GO intervention on the activity of liver cells, spleen cells and macrophages in mice. Note: (A) Liver cell activity; (B) Spleen cell activity; (C) Macrophage activity. 


\section{DISCUSSION}

As one of the perilous diseases usually induced by bacterial infection, sepsis invariably gives rise to fever, joint swelling and pain, and systemic inflammation [14]. Endotoxin is one of the key substances that leads to the patient's immune response by bacteria through invading macrophages and neutrophils, which is considered as one of the major causes of sepsis [15]. Studies have found that the binding of LPS and the TLR4 protein on the cell surface may induce cells to produce a large number of inflammatory factors [16]. At present, antibiotics are often used clinically to inhibit bacteria in patients with sepsis, though its neutralization effect on endotoxin toxicity were rather concealed [17]. That a predominant neutralization effect of AWRK6 antimicrobial peptides on the toxicity of LPS is able to mitigate the inflammatory response of cells triggered by LPS has also been reported. AWRK6 is a new type of cationic antibacterial peptide, possessing an $\alpha$-helical structure and an affinity for LPS [18]. This study targeted the therapeutic effect of AWRK6 on LPSinduced sepsis, and evaluated the application value of GO-loaded AWRK6 in the treatment of sepsis.

GO is a new type of active material that contains a large number of oxygen-containing functional groups, characterized by a positive biological activity, an excellent hydrophilicity and a stable dispersity in water, which is widely used in the chemical and medical areas [19]. Biodistribution analysis revealed that GO presented in mice brain, spleen, liver, kidney and bone marrow within a month after injection [20]. Eventually,
GO materials were mostly excreted through urinary system, whereas a small portion of GO would be sequestered by spleen [21, 22]. However, no detectable pathological consequences in the spleen were found to be caused by this GO accumulation [22]. In addition, analyses using both bright-field TEM coupled with electron diffraction and Raman spectroscopy spotted in vivo intracellular biodegradation of $\mathrm{GO}$, and the spectral features of GO crystals barely existed in spleen nine months after injection [22]. Meanwhile, GO is widely used in human. For example, it has been reported that Graphene and GO enhance ROS accumulation in human skin keratinocytes [23]. GO nanoplatelets improve anti-cancer effect of cisplatin on human lung cancer cells [24]. It has been found GO induces anti-angiogenic impact of GO in primary human endothelial cells [25].

It was found in this study that AWRK6/GO was more competent in the suppression of LPS activity in an in vitro environment than AWRK6, while LPS was barely affected by GO. A larger specific surface area enables GO to strongly absorb substances with a small molecular weight, indicating no evident inhibitory effect on LPS by GO. Compared with AWRK6, GO in AWRK6/GO elevates the drug's loading capacity, which further enhances the inhibitory effect of AWRK6 on LPS activity by increasing the possibility of interaction between AWRK6 and LPS. Several studies determined that GO could be engulfed by multiple cell types such as macrophages, natural killer cells and so on [26, 27]. GO could serve as an antioxidant to impair intracellular ROS accumulation, and attenuate
A

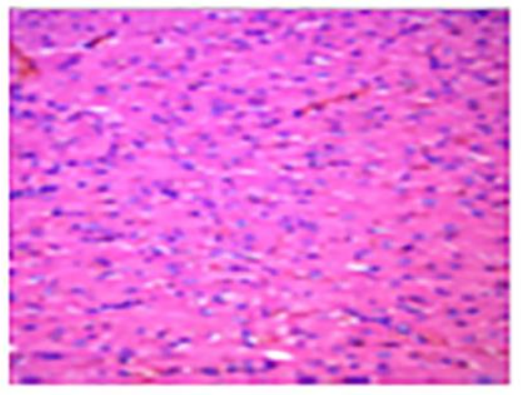

D

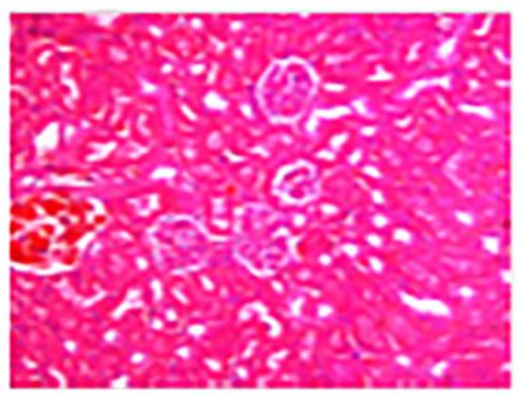

B

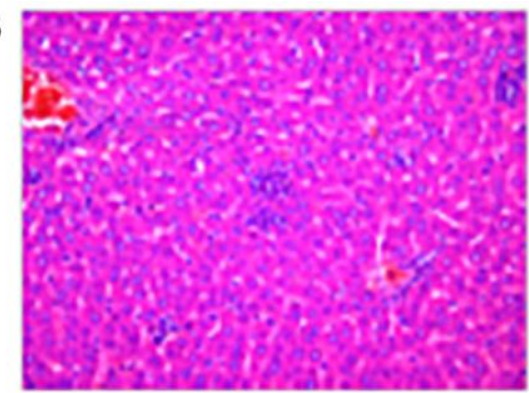

E

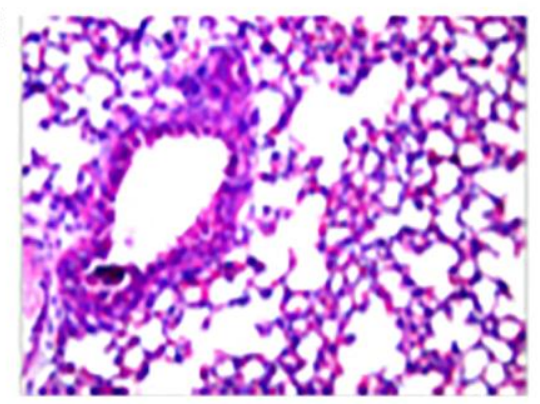

C

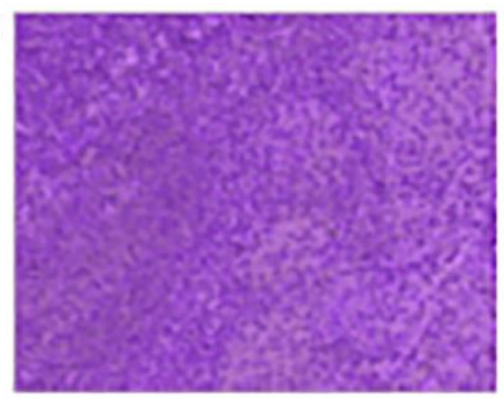

Figure 6. The effect of AWRK6/GO on mouse organs and tissues. Note: (A) Heart; (B) Liver; (C) Spleen; (D) Kidney; (E) Kidney. 
inflammatory polarization to type II macrophages [26]. Another study suggested that nanoformulated GO could stimulate neutrophile activation via inducing ROS formation [28]. On the other hand, Chen and colleagues reported no obvious cytotoxicity or significant cellular uptake of GO in A549 lung cancer cells at low dose, while higher dose of GO induced oxidative stress and slightly impaired the cell viabilities [29]. These data demonstrated that the diverse doses and functionalization notably altered the internalization and effects of GO on various cell types. Our data suggested that only high dose of AWRK6/GO cause slightly retarded viability of macrophage, yet the internalization of AWRK6/GO by macrophage, leukocytes and normal liver cells, as the inflammatory response still need to be explored in future studies. Moreover, the pharmacokinetics (PK) and pharmacodynamics (PD) of GO were widely studied by previous studies. For example, Zhang et al., reported that the GO shows a long blood circulation time (half-time $5.3 \pm 1.2 \mathrm{~h}$ ) [30]. The presence of GO in bladder gradually increases within 1 hour after injection and reached the maximum concentration after 6 hours [31]. Li and colleagues compared the retention of GO and GO-PEG, and found that GO particles retained partially in lung and mostly in liver and spleen, while PEG coating improves the biocompatibility of GO, decreasing its retention in liver, lung, and spleen. Yet both GO and GO-PEG were still detectable 3 months after injection [32]. We will analyze the PK and PD of GO in our system in future investigations.

Sepsis is an inflammatory reaction that affects the patient's systemic organs. A small amount of endotoxin can trigger a significant increase in the level of inflammatory factors in the body as it is highly sensitive to bacterial endotoxins [14]. IL-8 and TNF- $\alpha$, produced by monocytes-macrophages, can promote the body's inflammatory response and reflect the degree of inflammation, which are considered as vital indicators for the diagnosis of sepsis [33, 34]. Corresponding results discovered in this study that after LPS induction, the levels of IL- 8 and TNF- $\alpha$ in mouse whole blood and macrophages observed a sharp rise with LPS induction but a notable decline after intervention with AWRK6 or AWRK6/GO. Moreover, prior studies proved that AWRK6 can significantly improve the levels of IL-8 and TNF- $\alpha$ in LPS mice, and inhibit body inflammation [34]. Extended results in this study confirmed that in comparison with AWRK6, AWRK6/GO prominently drove down the level of inflammation in mouse whole blood and macrophages, suggesting that AWRK6/GO can optimize the inflammatory response in mice by elevating the ability to neutralize LPS. Moreover, HMGB1 is a nuclear protein that could be released by macrophages at late phase of LPS-caused inflammatory response [35]. In this work, we detected the early inflammatory response under LPS induction, which was represented by the levels of IL- 8 and TNF- $\alpha$. The HMGB1 levels released to blood system or in tissues at later phase was not detected, and would be discussed in future study.

In this study, mice were injected with $50 \mathrm{mg} / \mathrm{kg}$ of LPS, and then AWRK6 or AWRK6/GO was used to evaluate the application value of AWRK6/GO in the treatment of sepsis. The results showed that compared with LPS control mice, both AWRK6 and AWRK6/GO garnered a favorable outcome in ameliorating the survival time and survival rate of LPS mice. It has been stated by Jin et al. [36] that AWRK6 has a protective bearing on LPS-induced liver cells in mice, and can inhibit the liver cell apoptosis induced by LPS in mice by participating in the regulation of the intracellular MAPK signaling pathway. That the improvement of drug efficacy was achieved by the loading of GO that has a low toxicity has been reported [37]. Zhang et al. [38] confirmed that the GO-loaded pro-apoptotic polypeptide drug delivery system effectively inhibit the proliferation of cancer cells. Similar results were reported in this study that AWRK6/GO was more efficient and effective with regard to the amelioration of the survival time and survival rate of LPS mice than AWRK6. Vivo experiments displayed a survival rate of mice as high as $90 \%$ in the AWRK6/GO group seven days after the injection of AWRK6/GO, which was apparently higher than those of other groups, indicating a strong neutralization effect of AWRK6/GO on LPS and an elevation of inhibitory effect of AWRK6 on LPS activity in vivo.

In conclusion, the AWRK6/GO complex formed by loading AWRK6 with GO can remarkably enhance the inhibitory effect of AWRK6 on LPS toxicity, prolong the life cycle of LPS mice, and elevate the survival rate of LPS mice with good biological safety.

\section{MATERIALS AND METHODS}

\section{Preparation of GO}

Preparation: Added concentrated sulfuric acid into the graphene, fully stirred, slowly added potassium permanganate, fully stirred for 20 minutes, and continued stirring in a $35^{\circ} \mathrm{C}$ constant temperature water bath until the solution turned green; moved the solution from the $35^{\circ} \mathrm{C}$ water bath to the ice water bath, continued stirring till purple red smoke appeared, then continue stirring for another 30 minutes. Subsequently, added 4 times the volume of cold water to the solution, continued stirring until the solution turned brown, and added cold water again until the foam disappeared and 
the solution turned orange-yellow. Rinsed the precipitate with $10 \% \mathrm{HCL}$, water and absolute ethanol, and stripped the graphene oxide into GO by the ultrasonic dispersion method and dried.

\section{Preparation and characterization of AWRK6/GO}

Added $3 \mathrm{mg}$ of GO into $20 \mathrm{~mL}$ of AWRK6 solution (20 $\mathrm{mg} / \mathrm{L}$ ) for a 160 -minute reaction in a $30^{\circ} \mathrm{C}$ water bath shaker (130 revolutions/min). used hydrochloric acid and sodium hydroxide solution to adjust the $\mathrm{pH}$ value of the AWRK6 solution, filtered with a $0.45 \mu \mathrm{m}$ water phase filter, and dissolved AWRK6/GO with methanol.

Characterization of AWRK6/GO: AWRK6/GO was characterized by AFM and ultraviolet-visible spectrophotometer.

\section{Drug release}

The dialysis bag method was used to investigate the drug release rate in vitro. The GO nanoparticle solution loaded with AWRK6 was placed in $1 \mathrm{~mL}$ of PBS (pH 7.4 or $\mathrm{pH} 5.0$ ) containing $0.1 \%$ Tween 80 , put in a dialysis bag after it fully dispersed, and placed in a centrifugal tube containing $30 \mathrm{~mL}$ of the corresponding release medium. A vitro release test was performed in the shaker with $37^{\circ} \mathrm{C}$ and $100 \mathrm{rpm} .200 \mu \mathrm{L}$ of release medium were taken after $0.5,1,2,3,4,6,8,12,24$, and $48 \mathrm{~h}$, and an equal volume of fresh release medium was supplemented. The drug concentration in the release medium was determined by HPLC, and the cumulative release amount was calculated.

Chromatographic conditions: Diamonsil C18 (250 mm $\times 4.6 \mathrm{~mm}, 5.0 \mu \mathrm{m}$ ) chromatographic column was used to detect the solution, with a column temperature of $30^{\circ} \mathrm{C}$; the volume ratio of mobile phase acetonitrilewater solution was 30 to 70 ; the volume flow was $1 \mathrm{~mL} / \mathrm{min}$; UV detection wavelength was $306 \mathrm{~nm}$; sample volume was $10 \mathrm{uL}$; detection time was $15 \mathrm{~min}$. AWRK6 retention time was 5.2-7.5 $\mathrm{min}$. The formula for calculating drug loading and encapsulation efficiency (LC) was as follows:

$$
\begin{aligned}
\mathrm{EE} \% & =\mathrm{Wt} / \mathrm{Ws} \times 100 \% \\
\mathrm{LC} \% & =\mathrm{Wt} / \mathrm{Wo} \times 100 \%
\end{aligned}
$$

Note: Wt: the mass of AWRK6 contained in the nanoparticles; Wo: the initial dose of AWRK6; Ws: the total mass of the lyophilized nanoparticles.

\section{Neutralization of endotoxin by AWRK6/GO in vitro}

According to the treatment method, the 96-well plate with $10 \mu \mathrm{L}$ LPS (final concentration $0.2 \mathrm{ng} / \mathrm{mL}$ ) added in vitro was divided into LPS group, AWRK6 (20 $\mu \mathrm{g} / \mathrm{mL})$ group, GO $(20 \mu \mathrm{g} / \mathrm{mL})$ group and AWRK6/GO $(20 \mu \mathrm{g}) / \mathrm{mL})$ group. $10 \mu \mathrm{L}$ of the corresponding drug according to the group was added and incubated at $37^{\circ} \mathrm{C}$ for $30 \mathrm{~min}$. An ELISA kit was employed to detect the residual LPS content in the plate.

\section{Detection of IL-8 levels in whole blood of mice}

The ELISA method was used to detect the levels of IL-8 (SEKM-0046, Solarbio, China) and TNF- $\alpha$ (PT512, Beyotime, China) in the whole blood of mice. The blood from the heart of LPS mice in a heparinized tube was collected, $200 \mu \mathrm{L}$ of heparinized mouse blood was added to a 96-well plate containing $25 \mu \mathrm{L}$ LPS (final concentration $5 \mathrm{ng} / \mathrm{mL}$ ), and $25 \mu \mathrm{L}$ AWRK6 (20 $\mu \mathrm{g} / \mathrm{mL})$, GO $(20 \mu \mathrm{g} / \mathrm{mL})$ and AWRK6/GO $(20 \mu \mathrm{g} / \mathrm{mL})$ were added and incubated at $37^{\circ} \mathrm{C}$ for 24 hours and centrifuged at $1200 \mathrm{rmp} / \mathrm{min}$ for 8 minutes. The upper layer of plasma was analyzed by ELISA for the inflammatory factor IL- 8 levels. The animal study was reviewed and approved by Linyi People's Hospital.

\section{Detection of TNF- $\alpha$ level in mouse macrophages}

The ELISA method was used to detect the level of TNF- $\alpha$ in mouse peritoneal macrophages. The macrophages were inoculated in a 96-well plate at $2 \times 105$ cells/well, and $25 \mu \mathrm{L}$ of AWRK6 $(20 \mu \mathrm{g} / \mathrm{mL})$, GO $(20 \mu \mathrm{g} / \mathrm{mL})$ and AWRK6/GO $(20 \mu \mathrm{g} / \mathrm{mL})$ and 25 $\mu \mathrm{L}$ LPS (final concentration $5 \mathrm{ng} / \mathrm{mL}$ ) were added and incubated in a constant temperature incubator at $37^{\circ} \mathrm{C}$ for 6 hours; The ELISA method was used to detect the content of TNF- $\alpha$ in cells (PT512, Beyotime, China).

\section{Observation of the effect of AWRK6/GO on the survival rate of LPS mice}

Construction of a mouse model of endotoxin sepsis: $0.5 \mathrm{~mL}$ of LPS with a concentration of $50 \mathrm{mg} / \mathrm{kg}$ was injected intraperitoneally into mice to construct a mouse model. LPS mice were randomly divided into LPS control group, AWRK6 group, GO group and AWRK6/GO group. The AWRK6, GO and AWRK6/GO groups were injected with AWRK6, GO or AWRK6/GO at $10 \mathrm{mg} / \mathrm{kg}$, respectively. The survival status of the mice was recorded every 8 hours, and the observation was continued for 7 days.

\section{Biosafety evaluation of AWRK6/GO}

The toxicity of AWRK6/GO in the liver cells, splenic lymphocytes and peritoneal macrophages of mice was determined by CCK-8 test. Mice hepatocytes, spleen lymphocytes and peritoneal macrophages $\left(1 \times 10^{4}\right.$ cells/well) in the logarithmic growth phase were planted 
in 96-well plates, and AWRK6/GO $(20 \mu \mathrm{g} / \mathrm{mL})$ was added with concentrations of $10,20,30,40 \mu \mathrm{M}$. After 24 hours, $10 \mu \mathrm{L}$ of CCK- 8 reaction solution was added to each well, and incubated in a constant temperature incubator for 4 hours. The absorbance at $450 \mathrm{~nm}$ on the microplate reader was detected.

The visceral tissues of mice injected with the drug AWRK6/GO for 20 days were examined by immunohistochemistry, and the pathological changes of the mice's organs were observed. Immunohistochemical method: Mice injected with different drugs into the abdominal cavity were killed by cervical dislocation, and the heart, liver, spleen, lung and kidney tissues were collected. The tissues of mice were rinsed with PBS solution of $\mathrm{pH} 7.4$, placed in $10 \%$ neutral formalin solution, and fixed at $25^{\circ} \mathrm{C}$ for 24 hours; the tissue samples were dehydrated by gradient concentration of ethanol, placed in xylene for 20 minutes until it became transparent, and embedded in paraffin at $60^{\circ} \mathrm{C}$ for 2 hours. The paraffin-embedded tissues were cut into sections with a thickness of $5 \mu \mathrm{m}$, extended in a $42^{\circ} \mathrm{C}$ water bath until they became transparent, loaded on a glass slide, heated an oven at $75^{\circ} \mathrm{C}$ for 1 hour and dewaxed with xylene till they became transparent; $100 \%, 95 \%$, and $85 \%$ gradient concentration of ethanol was used for rehydration; hematoxylin was added dropwise onto the section for nuclear staining for 10 min, and rinsed with distilled water. After the sections were differentiated in hydrochloric acid-ethanol solution for 30 s, they were rinsed again with distilled water and placed in $1 \%$ ammonia water to return to blue for 30 minutes; the sections were stained with $0.5 \%$ eosin staining solution for 3 minutes, rinsed with distilled water, dehydrated with $85 \%, 95 \%$ and $100 \%$ ethanol in sequence, and dealcoholized in xylene; neutral balsam was used for mounting.

\section{Cell lines}

Mouse peritoneal macrophages were isolated from C57BL/6 mice aged 6 to 8 weeks. In short, sterile 3\% thioglycollate medium $(1 \mathrm{ml})$ was intraperitoneally injected after a 4-day prelavage with $10 \mathrm{~mL}$ PBS, the macrophages were then elicited by thioglycolate. Mouse hepatocytes and spleen lymphocytes were obtained following a reported protocol [39]. All cells were maintained in RPMI-1640 medium added with $10 \%$ FBS (Hyclone, USA), $100 \mathrm{U} / \mathrm{mL}$ penicillin and $100 \mathrm{U} / \mathrm{mL}$ streptomycin (Sigma, USA), and cultured in a humidified $37^{\circ} \mathrm{C}$ incubator filled with $5 \% \mathrm{CO}_{2}$.

\section{Data analysis}

The experiments involved in this study were carried out independently three times, and the data obtained were processed by SPSS 20.0 and graphed by GraphPad Prism 7. The measurement data were analyzed by variance analysis. A $t$-test was used for the difference between the two groups, and Bonferroni test was for the difference between multiple groups, recorded as the mean \pm standard deviation. A difference was considered statistically significant when a $p$ value was less than 0.05 .

\section{AUTHOR CONTRIBUTIONS}

Bo Song and Hongli Zhao contributed to the study design, performed experiments and reviewed the manuscript. Haiyan Yang analyzed the data and writing of the manuscript. Shengji Wang contributed to the data collection, data interpretation and manuscript writing. All authors read and approved the final manuscript.

\section{CONFLICTS OF INTEREST}

The authors declare that the research was conducted in the absence of any commercial or financial relationships that could be construed as a potential conflict of interest.

\section{FUNDING}

This study was supported by Linyi People's Hospital.

\section{REFERENCES}

1. Cheng CG, Chien WC, Lin HC, Lin HC, Chung CH, Cheng CA. Hearing impairment in young and middle-aged septicemia survivors. Medicine (Baltimore). 2020; 99:e21050. https://doi.org/10.1097/MD.0000000000021050 PMID:32702847

2. Alam MS, Pillai KK, Abdi SAH, Kapur P, Pillai PK, Nagarajan K. Adverse drug reaction monitoring during antimicrobial therapy for septicemia patients at a university hospital in New Delhi. Korean J Intern Med. 2018; 33:1203-09.

https://doi.org/10.3904/kjim.2016.001 PMID:28874042

3. Khan AU, Muhammad Khan A, Khan A, Shal B, Aziz A, Ahmed MN, Khan $S$. The newly synthesized compounds (NCHDH and NTHDH) attenuates LPSinduced septicemia and multi-organ failure via Nrf2/HO1 and HSP/TRVP1 signaling in mice. Chem Biol Interact. 2020; 329:109220. https://doi.org/10.1016/i.cbi.2020.109220 PMID: $\underline{2763245}$

4. Li L, Shu MQ, Chen J. CYLD deficiency exacerbates lipopolysaccharide (LPS)-induced pyroptosis in 
astrocytes of mice with sepsis. Biochem Biophys Res Commun. 2019; 514:1066-73.

https://doi.org/10.1016/j.bbrc.2019.05.033

PMID:31097224

5. Kimura $M$, Kosuge $K$, Ko $Y$, Kurosaki N, Tagawa N, Kato I, Uchida Y. Potent Antibacterial Activity of Synthetic Peptides Designed from Salusin- $\beta$ and HIV-1 Tat(49-57). Chem Pharm Bull (Tokyo). 2020; 68:810-13.

https://doi.org/10.1248/cpb.c20-00209

PMID: $\underline{32448814}$

6. Aldilla VR, Chen R, Martin AD, Marjo CE, Rich AM, Black DS, Thordarson P, Kumar N. Anthranilamidebased Short Peptides Self-Assembled Hydrogels as Antibacterial Agents. Sci Rep. 2020; 10:770. https://doi.org/10.1038/s41598-019-57342-6 PMID: 31964927

7. Su BC, Huang HN, Lin TW, Hsiao CD, Chen JY. Epinecidin-1 protects mice from LPS-induced endotoxemia and cecal ligation and puncture-induced polymicrobial sepsis. Biochim Biophys Acta Mol Basis Dis. 2017; 1863:3028-37.

https://doi.org/10.1016/i.bbadis.2017.08.032 PMID:28882626

8. Fisher AB, Dodia C, Chatterjee S, Feinstein SI. A Peptide Inhibitor of NADPH Oxidase (NOX2) Activation Markedly Decreases Mouse Lung Injury and Mortality Following Administration of Lipopolysaccharide (LPS). Int J Mol Sci. 2019; 20:2395.

https://doi.org/10.3390/ijms20102395

PMID:31096551

9. Zhang X, Gao S, Liu M, Wei N, Zhang Q, Li X, Niu X. Novel XTENylated AWRK6 analog with hypoglycemic activity, and anti-HSV-2 potential in combination with double shRNA. Life Sci. 2021; 274:119313.

https://doi.org/10.1016/i.Ifs.2021.119313

PMID:33667511

10. Mahmoudi E, Azizkhani S, Mohammad AW, Ng LY, Benamor A, Ang WL, Ba-Abbad M. Simultaneous removal of Congo red and cadmium(II) from aqueous solutions using graphene oxide-silica composite as a multifunctional adsorbent. J Environ Sci (China). 2020; 98:151-60.

https://doi.org/10.1016/j.jes.2020.05.013

PMID:33097147

11. Wong SHM, Lim SS, Tiong TJ, Show PL, Zaid HFM, Loh HS. Preliminary In Vitro Evaluation of ChitosanGraphene Oxide Scaffolds on Osteoblastic Adhesion, Proliferation, and Early Differentiation. Int J Mol Sci. 2020; 21:5202.

https://doi.org/10.3390/ijms21155202

PMID: $\underline{32708043}$
12. Chen S, Shi M, Xu Q, Xu J, Duan X, Gao Y, Lu L, Gao F, Wang $\mathrm{X}, \mathrm{Yu} \mathrm{Y}$. $\mathrm{Ti}_{3} \mathrm{C}_{2} \mathrm{~T}_{x} \mathrm{MXene/nitrogen-doped} \mathrm{reduced}$ graphene oxide composite: a high-performance electrochemical sensing platform for adrenaline detection. Nanotechnology. 2021; 32:265501.

https://doi.org/10.1088/1361-6528/abef94

PMID:33730698

13. Liu C, Luo X. Potential molecular and graphene oxide chelators to dissolve amyloid- $\beta$ plaques in Alzheimer's disease: a density functional theory study. J Mater Chem B. 2021; 9:2736-46.

https://doi.org/10.1039/d0tb02985h

PMID:33688880

14. Pfalzgraff A, Heinbockel L, Su Q, Brandenburg K, Weindl G. Synthetic anti-endotoxin peptides inhibit cytoplasmic LPS-mediated responses. Biochem Pharmacol. 2017; 140:64-72.

https://doi.org/10.1016/i.bcp.2017.05.015

PMID:28539262

15. Watts BA 3rd, Tamayo E, Sherwood ER, Good DW. Monophosphoryl lipid A pretreatment suppresses sepsis- and LPS-induced proinflammatory cytokine production in the medullary thick ascending limb. Am J Physiol Renal Physiol. 2020; 319:F8-18. https://doi.org/10.1152/ajprenal.00178.2020 PMID:32421349

16. Pfalzgraff $A$, Correa $W$, Heinbockel L, Schromm AB, Lübow C, Gisch N, Martinez-de-Tejada G, Brandenburg K, Weindl G. LPS-neutralizing peptides reduce outer membrane vesicle-induced inflammatory responses. Biochim Biophys Acta Mol Cell Biol Lipids. 2019; 1864:1503-13.

https://doi.org/10.1016/j.bbalip.2019.05.018 PMID:31163264

17. Nagaoka I, Tamura H, Reich J. Therapeutic Potential of Cathelicidin Peptide LL-37, an Antimicrobial Agent, in a Murine Sepsis Model. Int J Mol Sci. 2020; 21:5973.

https://doi.org/10.3390/ijms21175973 PMID: $\underline{32825174}$

18. Wang $Q$, Jin $L$, Wang $H$, Tai $S$, Liu H, Zhang D. AWRK6, A Synthetic Cationic Peptide Derived from Antimicrobial Peptide Dybowskin-2CDYa, Inhibits Lipopolysaccharide-Induced Inflammatory Response. Int J Mol Sci. 2018; 19:600.

https://doi.org/10.3390/ijms19020600 PMID:29463000

19. Novodchuk I, Kayaharman M, Ausri IR, Karimi R, Tang XS, Goldthorpe IA, Abdel-Rahman E, Sanderson J, Bajcsy M, Yavuz M. An ultrasensitive heart-failure BNP biosensor using $\mathrm{B} / \mathrm{N}$ co-doped graphene oxide gel FET. Biosens Bioelectron. 2021; 180:113114. https://doi.org/10.1016/i.bios.2021.113114 PMID:33676163 
20. Cherian RS, Anju S, Paul W, Sabareeswaran A, Mohanan PV. Organ distribution and biological compatibility of surface-functionalized reduced graphene oxide. Nanotechnology. 2020; 31:075303. https://doi.org/10.1088/1361-6528/ab4bff PMID:31593929

21. Jasim DA, Ménard-Moyon C, Bégin D, Bianco A, Kostarelos $\mathrm{K}$. Tissue distribution and urinary excretion of intravenously administered chemically functionalized graphene oxide sheets. Chem Sci. 2015; 6:3952-64.

https://doi.org/10.1039/c5sc00114e PMID:28717461

22. Newman L, Jasim DA, Prestat E, Lozano N, de Lazaro I, Nam Y, Assas BM, Pennock J, Haigh SJ, Bussy C, Kostarelos K. Splenic Capture and In Vivo Intracellular Biodegradation of Biological-Grade Graphene Oxide Sheets. ACS Nano. 2020; 14:10168-86.

https://doi.org/10.1021/acsnano.0c03438 PMID: 32658456

23. Pelin $M$, Fusco L, Martín C, Sosa S, Frontiñán-Rubio J, González-Domínguez JM, Durán-Prado $M$, Vázquez $E$, Prato M, Tubaro A. Graphene and graphene oxide induce ROS production in human $\mathrm{HaCaT}$ skin keratinocytes: the role of xanthine oxidase and $\mathrm{NADH}$ dehydrogenase. Nanoscale. 2018; 10:11820-30.

https://doi.org/10.1039/c8nr02933d

PMID:29920573

24. Rosli NF, Fojtů M, Fisher AC, Pumera M. Graphene Oxide Nanoplatelets Potentiate Anticancer Effect of Cisplatin in Human Lung Cancer Cells. Langmuir. 2019; 35:3176-82.

https://doi.org/10.1021/acs.langmuir.8b03086 PMID: 30741550

25. Cibecchini G, Veronesi M, Catelani T, Bandiera T, Guarnieri D, Pompa PP. Antiangiogenic Effect of Graphene Oxide in Primary Human Endothelial Cells. ACS Appl Mater Interfaces. 2020; 12:22507-18.

https://doi.org/10.1021/acsami.0c03404 PMID: 32255338

26. Han J, Kim YS, Lim MY, Kim HY, Kong S, Kang M, Choo YW, Jun JH, Ryu S, Jeong HY, Park J, Jeong GJ, Lee JC, et al. Dual Roles of Graphene Oxide To Attenuate Inflammation and Elicit Timely Polarization of Macrophage Phenotypes for Cardiac Repair. ACS Nano. 2018; 12:1959-77.

https://doi.org/10.1021/acsnano.7b09107 PMID:29397689

27. Yan J, Chen L, Huang CC, Lung SC, Yang L, Wang WC, Lin $\mathrm{PH}$, Suo $\mathrm{G}$, Lin $\mathrm{CH}$. Consecutive evaluation of graphene oxide and reduced graphene oxide nanoplatelets immunotoxicity on monocytes. Colloids Surf B Biointerfaces. 2017; 153:300-09. https://doi.org/10.1016/i.colsurfb.2017.02.036 PMID:28285061

28. Lu YJ, Wang YH, Sahu RS, Chen JP, Dash BS, Chung PJ, Yang HW, Chuang EY, Hwang TL. Mechanism of Nanoformulated Graphene Oxide-Mediated Human Neutrophil Activation. ACS Appl Mater Interfaces. 2020; 12:40141-52.

https://doi.org/10.1021/acsami.0c12490

PMID: $\underline{32845120}$

29. Cheng L, Yang K, Li Y, Chen J, Wang C, Shao M, Lee ST, Liu Z. Facile preparation of multifunctional upconversion nanoprobes for multimodal imaging and dual-targeted photothermal therapy. Angew Chem Int Ed Engl. 2011; 50:7385-90.

https://doi.org/10.1002/anie.201101447 PMID:21714049

30. Zhang X, Yin J, Peng C, Hu W, Zhu Z, Li W, Fan C, Huang $Q$. Distribution and biocompatibility studies of graphene oxide in mice after intravenous administration. Carbon. 2011; 49:986-95.

31. Li B, Yang J, Huang Q, Zhang Y, Peng C, Zhang Y, He Y, Shi J, Li W, Hu J, Fan C. Biodistribution and pulmonary toxicity of intratracheally instilled graphene oxide in mice. NPG Asia Materials. 2013; 5:e44-e.

32. Li B, Zhang $X Y$, Yang JZ, Zhang YJ, Li WX, Fan $\mathrm{CH}$, Huang $Q$. Influence of polyethylene glycol coating on biodistribution and toxicity of nanoscale graphene oxide in mice after intravenous injection. Int J Nanomedicine. 2014; 9:4697-707.

https://doi.org/10.2147/IJN.S66591 PMID:25356071

33. Sobouti B, Ghavami Y, Asadifar B, Jafarzadeh M, Ghelman M, Vaghardoost R. Determination of Serum Levels of Interleukin-6, Interleukin-8, Interleukin-10, and Tumor Necrosis-Alpha and their Relationship With The Total Body Surface Area in Children. J Burn Care Res. 2020; 41:539-43.

https://doi.org/10.1093/jbcr/irz180

PMID:31701129

34. He Y, Du WX, Jiang HY, Ai Q, Feng J, Liu Z, Yu JL. Multiplex Cytokine Profiling Identifies Interleukin-27 as a Novel Biomarker For Neonatal Early Onset Sepsis. Shock. 2017; 47:140-47. https://doi.org/10.1097/SHK.0000000000000753 PMID:27648693

35. Abdulmahdi W, Patel D, Rabadi MM, Azar T, Jules E, Lipphardt M, Hashemiyoon R, Ratliff BB. HMGB1 redox during sepsis. Redox Biol. 2017; 13:600-07. https://doi.org/10.1016/i.redox.2017.08.001 PMID:28806702

36. Jin L, Wang $Q$, Zhang $H$, Tai S, Liu H, Zhang D. A Synthetic Peptide AWRK6 Alleviates 
Lipopolysaccharide-Induced Liver Injury. Int J Mol Sci. 2018; 19:2661.

https://doi.org/10.3390/ijms19092661

PMID:30205524

37. Chu F, Li K, Li X, Xu L, Huang J, Yang Z. Graphene Oxide Ameliorates the Cognitive Impairment Through Inhibiting PI3K/Akt/mTOR Pathway to Induce Autophagy in AD Mouse Model. Neurochem Res. 2021; 46:309-25.

https://doi.org/10.1007/s11064-020-03167-z

PMID:33180247

38. Zhang J, Chen L, Shen B, Chen L, Mo J, Feng J. DualSensitive Graphene Oxide Loaded with Proapoptotic Peptides and Anticancer Drugs for Cancer Synergetic Therapy. Langmuir. 2019; 35:6120-28. https://doi.org/10.1021/acs.langmuir.9b00611

PMID: 30983368

39. McCall CE, Zabalawi M, Liu T, Martin A, Long DL, Buechler NL, Arts RJW, Netea M, Yoza BK, Stacpoole PW, Vachharajani V. Pyruvate dehydrogenase complex stimulation promotes immunometabolic homeostasis and sepsis survival. JCI Insight. 2018; 3:e99292.

https://doi.org/10.1172/jci.insight.99292

PMID: $\underline{30089711}$ 